\title{
Cost savings associated with an MRI based strategy in suspected severe mitral regurgitation
}

\author{
Seth Uretsky ${ }^{1}$, Edgar Argulian², Hira Awan², Ashadevi Jagarlamudi ${ }^{2}$, Steven Wolff ${ }^{3 *}$ \\ From 19th Annual SCMR Scientific Sessions \\ Los Angeles, CA, USA. 27-30 January 2016
}

\section{Background}

Recent studies have shown that echocardiography and MRI are often discordant when assessing the severity of mitral regurgitation (MR), with echocardiography often overestimating severity of mitral regurgitation compared to MRI (1). This is particularly true among patients who underwent mitral valve surgery based on echocardiographic assessment and the current ACC/AHA recommendations for valvular disease. These findings not only have potential impact on patient management it also has an impact on the healthcare costs associated with mitral valve surgery.

\section{Methods}

We prospectively enrolled 115 (61 \pm 14 yrs, male $67 \%)$ patients with MR in a multicenter trial that underwent evaluation with both echocardiography and MRI. Each echocardiogram and MRI study was assessed for the severity of MR. Appropriateness of surgery was determined based on the ACC/AHA recommendations. The cost of mitral valve surgery was estimated conservatively as $\$ 30,000$ based on prior publications (2). The cost of echocardiography (\$264.48) and MRI (\$431.80) was based on Medicare part B reimbursement.

\section{Results}

Among the 115 patients, 40 (35\%) patients underwent indicated mitral valve surgery based on echocardiographic evaluation of MR severity and the ACC/AHA guidelines, with $93 \%$ having a class I indication and $7 \%$ having a class IIa indication. Of the 40 patients who underwent mitral valve surgery, 14 (35\%) had a class I indication by MRI and 26 (65\%) did not have an indication for mitral valve surgery. Based on cost estimates, an MRI based strategy would of resulted in a savings of $\$ 762,728$ in our study cohort (Table 1).

\section{Conclusions}

In patients referred for mitral valve surgery based on echocardiographic assessment and ACC/AHA guidelines, an MRI based strategy would have resulted in a cost savings of more than $\$ 19,068$ per patient. This estimate is conservative because it does not include costs related to surgery, such as patient morbidity or the need for long term anticoagulation and monitoring. According to a recent study (3), there are approximately 5,890 isolated mitral valve surgeries per year for patients with mitral regurgitation. Based on these findings, an MRI based strategy applied to all of the US could potentially result in a cost savings to the healthcare system of more than $\$ 100$ million annually.

\section{Authors' details}

${ }^{1}$ Cardiovascular Medicine, Morristown Medical Center, Morristown, NJ, USA. ${ }^{2}$ Medicine, Mount Sinai St. Luke's Hospital, New York, NY, USA. ${ }^{3}$ Radiology, Carnegie Hill Radiology, New York, NY, USA.

Published: 27 January 2016

Table 1 Cost differences between an echocardiography based strategy vs. an MRI based strategy

\begin{tabular}{ccc}
\hline & $\begin{array}{c}\text { Echocardiography based } \\
\text { strategy }\end{array}$ & $\begin{array}{c}\text { MRI based } \\
\text { strategy }\end{array}$ \\
\hline Echocardiography & $\$ 10,739.20$ & $\$ 10,739.20$ \\
MRI & & $\$ 17,272.00$ \\
Surgery & $\$ 1,200,000$ & $\$ 420,000$ \\
Total Costs & $\$ 1,210,739.20$ & $\$ 448,011.20$ \\
\hline
\end{tabular}

${ }^{3}$ Radiology, Carnegie Hill Radiology, New York, NY, USA

Full list of author information is available at the end of the article 


\section{References}

1. Uretsky $\mathrm{S}$, et al: Discordance between echocardiography and MRI in the assessment of mitral regurgitation severity: a prospective multicenter trial. J Am Coll Cardiol 2015, 65(11):1078-88, Mar 24.

2. Suri RM, et al: Improving affordability through innovation in the surgical treatment of mitral valve disease. Mayo Clinic proceedings 2013, 88(10):1075-84.

3. Gammie JS, et al: Trends in mitral valve surgery in the United States: results from the Society of Thoracic Surgeons Adult Cardiac Surgery Database. Ann Thorac Surg 2009, 87(5):1431-7, May.

doi:10.1186/1532-429X-18-S1-0134

Cite this article as: Uretsky et al:: Cost savings associated with an MRI based strategy in suspected severe mitral regurgitation. Journal of Cardiovascular Magnetic Resonance 2016 18(Suppl 1):O134.

Submit your next manuscript to BioMed Central and take full advantage of:

- Convenient online submission

- Thorough peer review

- No space constraints or color figure charges

- Immediate publication on acceptance

- Inclusion in PubMed, CAS, Scopus and Google Scholar

- Research which is freely available for redistribution

Submit your manuscript at www.biomedcentral.com/submit 